\title{
Quality of midwifery led care: assessing the effects of different models of continuity for women's satisfaction
}

\author{
Myfanwy Morgan, Natalie Fenwick, Christina McKenzie, Charles D A Wolfe
}

\begin{abstract}
Background-Changing Childbirth (1993), a report on the future of maternity services in the United Kingdom, endorsed the development of a primarily community based midwifery led service for normal pregnancy, with priority given to the provision of "woman centred care". This has led to the development of local schemes emphasising continuity of midwifery care and increased choice and control for women.

Aims-To compare two models of midwifery group practices (shared caseload and personal caseload) in terms of: (a) the extent to which women see the same midwife antenatally and know the delivery midwife, and $(b)$ women's preferences for continuity and satisfaction with their care.
\end{abstract}

Methods-A review of maternity case notes and survey of a cohort of women at 36 weeks of gestation and 2 weeks postpartum who attended the two midwifery group practices. Questionnaires were completed by 247 women antenatally (72\% response) and $222(68 \%)$ postnatally. Outcome measures were the level of continuity experienced during antenatal, intrapartum, and postnatal care, women's preferences for continuity of carer, and ratings of satisfaction with care.

Department of Public Health Medicine, United Medical and Dental School, London Myfanwy Morgan, reader in sociology of health Natalie Fenwick, research associate

Charles D A Wolfe, senior lecturer in public health medicine

Guy's and St Thomas' Hospitals Trust, London

Christina McKenzie,

director of midwifery services

Correspondence to: Dr M Morgan, Department of Public Health Medicine, United Medical and Dental Schools, St Thomas'

Hospital, London SE1 7EH, UK. Tel: 0171-928-9292 ext 3142; fax: 0171-928-1468.

Accepted for publication 2 March 1997 women's satisfaction are the ethos of care emphasising friendliness and support, the consistency of care, good communication, and participation in decisions.

(Quality in Health Care 1998;7:77-82)

Keywords: continuity of care; midwifery; service evaluation; satisfaction

\section{Introduction}

Maternity care in the United Kingdom has traditionally been based on a medically oriented model, with responsibility for care shared by community and hospital based midwives, general practitioners, and obstetricians. This has led to a fragmentation of services and what is often viewed as an impersonal "conveyor belt" style of care. ${ }^{1}$ To consider these issues the government set up an Expert Maternity Group "to review policy on NHS (National Health Service) maternity care, particularly during childbirth, and make recommendations." Their report, Changing Childbirth $(1993)^{2}$ formed a manifesto for change in maternity services in the United Kingdom towards a primarily community based midwifery led service for normal pregnancy, with priority given to the provision of woman centred care. Three requirements in achieving a woman centred service were identified as continuity of carer, and the provision of increased choice and control over their care by women and their partners. The report was not prescriptive as to the pattern of service use that should be adopted, recognising that this would vary according to local circumstances. However 10 indicators of success to be achieved within five years were identified, including that every woman should know one midwife who ensures continuity of her care (the named midwife) and that at least $75 \%$ of women should know the person who cares for them during their delivery.

The emphasis given by Changing Childbirth to continuity of care thus goes beyond technical continuity of the provision of care in a consistent way and emphasises personal continuity of care by known people. The importance attached to personal continuity in midwifery care, as in other areas of service provision, is based on a belief in the importance of human relations and their influence on the process and outcomes of care. At a psychosocial level the support and reassurance provided by familiar midwives during pregnancy, delivery, and postnatally have been linked with increased satisfaction for women, and feelings of control and involvement in decisions about their care. ${ }^{3}$ The provision of social support during pregnancy has also been shown to be associated with improved physical 


\begin{tabular}{|c|c|c|}
\hline & Shared caseload group practice & Personal caseload group practice \\
\hline Size & \multicolumn{2}{|c|}{ Team of six midwives } \\
\hline On call & \multicolumn{2}{|c|}{$\begin{array}{l}\text { Midwives work an on call rota to enable cover to be provided } 24 \text { hours a day. Women are able to } \\
\text { contact the midwives through a pager system }\end{array}$} \\
\hline Referrals & $\begin{array}{l}\text { Referrals received from over } 20 \text { GPs who } \\
\text { refer only some women to midwifery group } \\
\text { practice care (mainly based on geographical } \\
\text { area of residence) with some self referral }\end{array}$ & $\begin{array}{l}\text { Referrals from three GP practices who refer all } \\
\text { their women to midwifery group practice care }\end{array}$ \\
\hline Antenatal care & $\begin{array}{l}\text { Different midwives see women at weekly } \\
\text { antenatal clinic held in health centre }\end{array}$ & $\begin{array}{l}\text { Each woman assigned a named midwife who } \\
\text { provides most of her antenatal care. Antenatal } \\
\text { care held on three sites, one pair of midwives } \\
\text { assigned to each location }\end{array}$ \\
\hline Care during delivery & \multicolumn{2}{|c|}{$\begin{array}{c}\text { Women encouraged to attend "meet your midwife" sessions to increase their chance of knowing } \\
\text { their delivery midwife }\end{array}$} \\
\hline Postnal care & \multicolumn{2}{|c|}{$\begin{array}{l}\text { Intrapartum care provided by whichever member of the team is on call } \\
\text { Delivery midwives encouraged to visit women postnatally }\end{array}$} \\
\hline
\end{tabular}

Box 1 Organisation of care in midwifery group practice study sites.

and psychosocial outcomes for both mother and baby. ${ }^{45}$ Furthermore, by reducing the number of professionals involved, failures in communication and the likelihood of different prognoses and contradictory advice should be reduced. ${ }^{12}$

Since the publication of Changing Childbirth there has been a development in the United Kingdom of new forms of community based maternity services which provide all aspects of midwifery care (antenatal, intrapartum, and postnatal) to a defined caseload of women. ${ }^{6}$ However, these vary in their organisation and the type of personal continuity provided. One model identified in the scientific literature is "individual" caseload midwifery. This provides complete continuity by a named carer, and describes a situation in which the same midwife looks after a woman for all episodes in her maternity care and is on call 24 hours a day, seven days a week. A variant of this is a midwifery "partnership" where the caseload is shared between two midwives and most of the care is therefore provided by the named midwife and the rest by her partner, or occasionally by a larger group practice of midwives to which the partnership is affiliated. However, increasingly midwifery care is based on a group practice who share on call between the team. This may be organised on a "personal" caseload basis, with most of the

Table 1 Characteristics of respondents

\begin{tabular}{lcc}
\hline & $\begin{array}{c}\text { Shared caseload group } \\
\text { practice }(n=148) n(\%)\end{array}$ & $\begin{array}{c}\text { Personal caseload group } \\
\text { practice }(n=111) n(\%)\end{array}$ \\
\hline Ethnic group: & $105(71)$ & $47(44)$ \\
White & $9(6)$ & $6(6)$ \\
Black Caribbean & $18(12)$ & $40(37)$ \\
Black African & $1(1)$ & $10(8)$ \\
Bangladeshi & $15(10)$ & $8(7)$ \\
Other & & \\
Social class: & $61(41)$ & $14(13)$ \\
I and II Professional and intermediate & $30(20)$ & $12(11)$ \\
III Skilled non-manual & $13(9)$ & $26(23)$ \\
III Skilled manual & $12(8)$ & $4(4)$ \\
IV and V Semiskilled and unskilled & $4(3)$ & $26(23)$ \\
Student & $28(19)$ & \\
Unemployed or no answer & & $51(43)$ \\
Obstetric history: & $69(48)$ & \\
Previous child & & \\
\hline
\end{tabular}

Based on women who returned one or more questionnaires. antenatal care provided by a named midwife, and delivery and postnatal care undertaken by any member of the team, or as "shared" caseloads with care given by any member of the team through all phases of maternity care. As the recent report First Class Delivery: Improving Maternity Services in England ${ }^{1}$ notes, although it is clear that personal continuity of care is important it is not clear which is the best way of providing this. Several evaluations of midwifery led care have been undertaken, ${ }^{2-11}$ but there has been little comparison of group practice midwifery offering different models of continuity for women's preferences and satisfaction.

We investigated the effects of midwifery group practices organised as shared and personal caseloads in terms of: (a) the extent to which women see the same midwife antenatally and know the delivery midwife, and (b) women's preferences for antenatal continuity, knowing the delivery midwife, and satisfaction with their care.

Both midwifery group practices in our investigation were set up in December 1994 as pilot sites by a hospital trust in response to Changing Childbirth. They were close, in an inner London area, although the catchment for one group practice was predominantly council flats whereas the other was owner occupied terraced housing. Each group practice comprised a team of six midwives who were employed by the hospital trust. They worked in primary and secondary care to provide continuity of care over the antenatal, intrapartum, and postnatal period for a defined caseload of 200 women. Guidelines for referral to obstetricians in secondary care had been developed by all healthcare professionals. The only difference between the group practices was that one was organised entirely on a shared caseload model, whereas the other operated a personal caseload model in the provision of antenatal care with each woman being assigned a named midwife (box 1). However the personal caseload group practice emphasised that there was no guarantee of having their named midwife for the delivery, whereas it was expected that most women in the shared caseload group practices would know the delivery midwife. 


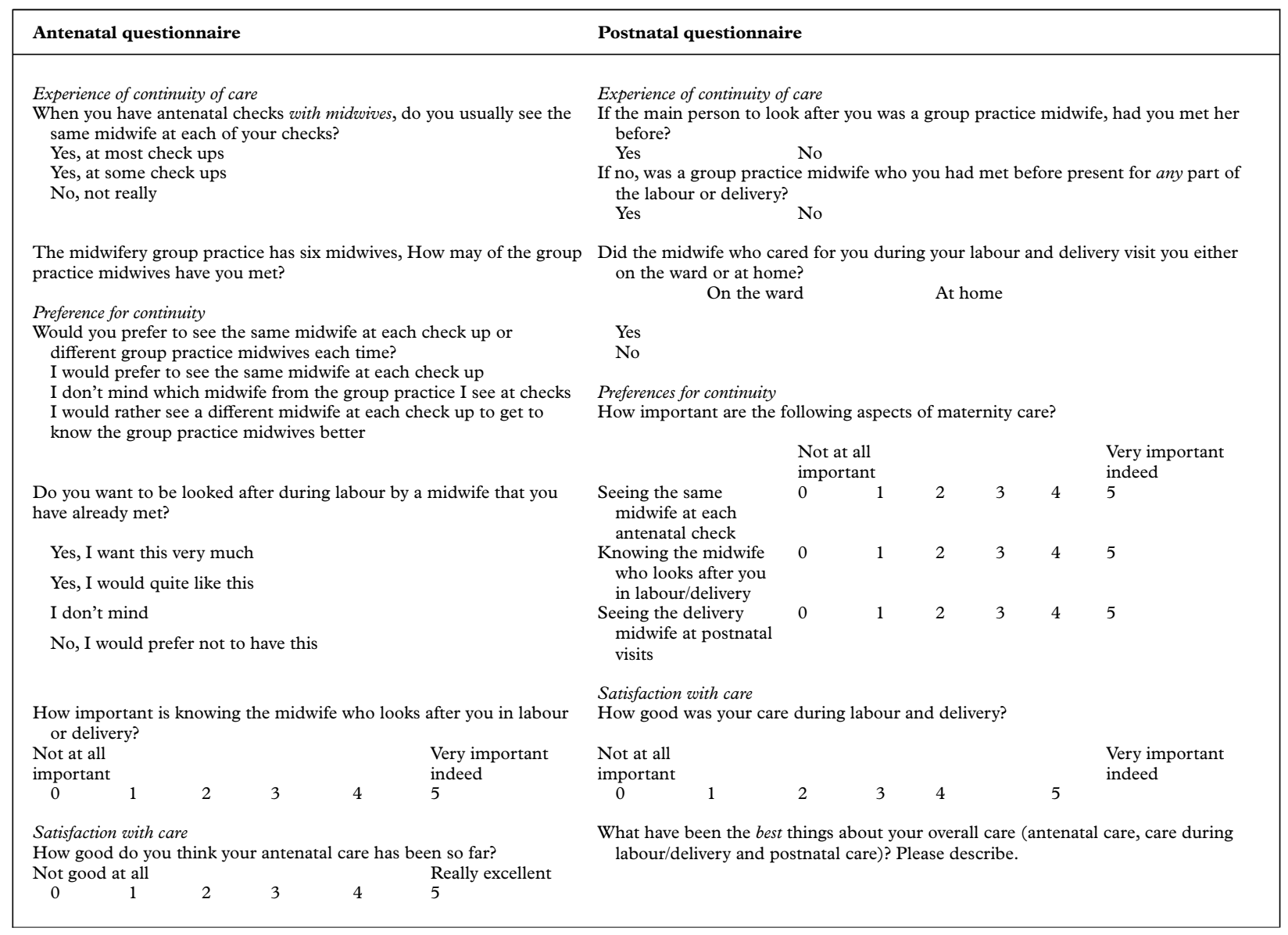

Box 2 Extracts from antenatal and postnatal questions.

\section{Methods}

DATA COLLECTION

Women's preferences and satisfaction were assessed through a survey of all women under the care of the two group practices who were due to deliver between November 151995 and September 15 1996. Two postal questionnaires were administered, one at 36 weeks of pregnancy (to 340 women) and one three weeks postnatally (to 327 women). Fewer questionnaires were sent out postnatally because 13 women had moved from the area and did not deliver with the group practice midwives. Reminder letters were sent to all women who did not return their questionnaires within two weeks, with a further reminder four weeks after the original mailing. Both initial and reminder letters were sent to Bengali women in their own language, and suggested that if they had problems understanding the questionnaire a family member or friend might be able to help them.

The questionnaire used standard questions to examine women's views. ${ }^{12}$ Likert scales were used to assess satisfaction with care $(0=$ no good at all, 5=excellent), and ratings of the importance of different aspects of care $(0=$ not at all important, 5=very important indeed). Open questions were used to identify what women thought were best and worst about their overall care. Answers to these open questions were classified into the main response categories identified from the data.
Data were abstracted from women's maternity case notes which were held by women during their care and returned to the group practice midwives at the final postnatal check. The case notes provided obstetric data and also validated women's own accounts of their experience of antenatal continuity. The total number of signatures by each professional group (midwives, general practitioners, and obstetricians) was recorded and antenatal continuity measured by counting the number of checks each woman received from the same midwife.

\section{STATISTICAL METHODS}

Univariate comparisons were made between the two models of care for continuity, and women's preferences and experiences for continuity. Categorical variables were analysed with the $\chi^{2}$ test and continuous variables with a non-normal distribution by the Mann-Whitney $U$ test. Logistic regression analysis was used to investigate the influence of social class, ethnicity, previous experience of maternity care (whether a first child), and practice variables, on: (a) preferences for antenatal continuity (comparing women who preferred to see the same midwife at each antenatal check with those who did not mind which midwife they saw or would prefer to see a different midwife at each check), (b) preferences for intrapartum care (comparing women who rated knowing the delivery midwife as score 5 , very important 
Table 2 Women's experiences of continuity of carer (data from the questionnaires)

\begin{tabular}{|c|c|c|c|}
\hline & \multicolumn{2}{|l|}{ Women $(n(\%))$} & \multirow[b]{2}{*}{$\begin{array}{l}\text { Significance } \\
\text { level }\end{array}$} \\
\hline & $\begin{array}{l}\text { Shared caseload } \\
\text { group practice }\end{array}$ & $\begin{array}{l}\text { Personal caseload } \\
\text { group practice }\end{array}$ & \\
\hline \multicolumn{4}{|l|}{ Antenatal care: } \\
\hline $\begin{array}{l}\text { Usually saw the same midwife at each } \\
\text { antenatal check }\end{array}$ & $47(35)$ & $83(80)$ & $<0.001^{\star}$ \\
\hline Had met $\geqslant 4$ midwives in the team & $85(62)$ & $35(32)$ & $<0.001 \dagger$ \\
\hline \multicolumn{4}{|l|}{ Intrapartum care: } \\
\hline Had met their main delivery midwife & $93(74)$ & $55(60)$ & \\
\hline Had met a midwife present during delivery & $19(15)$ & $13(14)$ & \\
\hline Had no midwife present they had met & $14(11)$ & $23(25)$ & $0.022^{\star} \ddagger$ \\
\hline \multicolumn{4}{|l|}{ Postnatal care: } \\
\hline $\begin{array}{l}\text { Were visited postnatally by their delivery } \\
\text { midwife }\end{array}$ & $95(76)$ & $76(84)$ & $0.257^{\star}$ \\
\hline
\end{tabular}

indeed, with those who rated this as score 4 or lower), and (c) satisfaction with antenatal and intrapartum care (comparing women who rated their care as score 5 excellent with those who rated it as score 4 or lower).

\section{Results}

SAMPLES

Antenatal questionnaires were returned by $247 / 340$ (73\%) women; 139/176 (79\%) women attending the shared caseload group practice, and 108/164 (66\%) women attending the personal caseload group practice. Postnatal questionnaires were returned by $222 / 327$ (68\%) women; $127 / 172$ (74\%) shared caseload midwifery; and 95/155 (61\%) personal caseload midwifery.

Data were abstracted from case notes for $77 \%(262 / 340)$ of the initial sample $(76 \%$ shared caseload midwifery and $79 \%$ personal caseload midwifery). The main reasons for exclusion were that women had retained their notes postnatally, or they were misfiled or missing from the hospital files.

The case note records indicated that women from ethnic minorities were overrepresented among non-responders to the postal questionnaire, and comprised 70\% (65/93) nonresponders to both questionnaires compared with $45 \%(211 / 469)$ of the total group. The higher non-response for the personal caseload midwifery practice was also largely accounted for by the greater prevalence of ethnic minorities attending this group practice.

\section{CHARACTERISTICS OF RESPONDENTS}

The two midwifery group practices served areas that differed in their socioeconomic and ethnic mix. This was reflected in the characteristics of attenders; higher proportions of respondents attending the shared caseload midwifery practice had a non-manual occupational classification (based on their own occupation or if this was missing, their partner's occupation) and classified themselves as white (table 1). The main groups of ethnic minorities were black African, black Caribbean, and Bangladeshi, with the last two groups being more prevalent among women attending the personal caseload midwifery practice.
The case notes indicated that the proportion of women with no previous child was very similar in the two group practices; $52 \%$ (70/134) for the shared caseload and 57\% (74/ 130) for the personal caseload. Altogether $83 \%$ (217/262) of women were identified clinically as low risk at booking, and according to the locally agreed guidelines did not require referral to an obstetrician due to any aspect of their booking history. The proportion was $84 \%$ (112/134) for the shared caseload group practice and $81 \%(105 / 130)$ for the personal caseload group practice.

\section{LEVEL OF CONTINUITY}

Data from the case notes indicated that $65 \%$ $(170 / 262)$ of women had antenatal checks with both midwives and their general practitioner and 35\% (92/262) had antenatal checks with midwives only. As well as these checks $40 \%$ $(105 / 262)$ were referred for obstetric opinion. Women who received antenatal care solely from midwives had a mean of 6.5 checks with midwives. Women who had input from a general practitioner had a similar mean of 6.4 checks with the midwives and a further mean of 2.4 checks with their general practitioner.

Signatures in women's case notes indicated that the women in the shared caseload group practice had significantly fewer antenatal checks with the same midwife than the women in the personal caseload group practice (mean $2.5 v 3.8, \mathrm{p}<0.001$, Mann-Whitney $U$ test). Altogether $40 \%(53 / 132)$ of women attending the shared caseload practice and 80\% (104/ 130) attending the personal caseload practice received three or more antenatal checks with the same midwife, and $11 \%(14 / 132)$ and $57 \%$ (74/130) respectively received four or more checks with the same midwife. The antenatal questionnaire (box 2) confirmed findings of the analysis of women's case notes; the women from the shared caseload group practice were more likely to see a different midwife at each antenatal check and to have met more midwives in the team. As a result, $74 \%$ (93/126) of the women from the shared caseload group practice recorded in the postnatal questionnaire that they had previously met their main delivery midwife compared with $60 \%(55 / 91)$ attending the personal caseload group practice (table 2).

The postnatal questionnaire identified no significant differences between group practices in the experience of postnatal continuity. Altogether $76 \%(95 / 126)$ of the women in the shared caseload group practice and $84 \%$ $(76 / 91)$ of these in the personal caseload group practice recorded that they were visited postnatally by the midwife who had looked after them during their labour and delivery.

WOMEN'S PREFERENCES FOR CONTINUITY

Women's responses to the antenatal questionnaire (box 2) indicated that only $25 \%(35 / 139)$ of the women from the shared caseload group practice preferred personal continuity of carer in the antenatal period, and $75 \%(104 / 139)$ did not mind which midwife they saw, or preferred to see a different midwife at each antenatal 
Table 3 Postnatal perceptions of the importance of different aspects of maternity care

\begin{tabular}{|c|c|c|c|}
\hline \multirow[b]{2}{*}{ Aspect of care } & \multicolumn{2}{|c|}{$\begin{array}{l}\text { Women rating each aspect as } \\
\text { very important indeed }(n(\%))\end{array}$} & \multirow[b]{2}{*}{$\begin{array}{l}\text { Significance } \\
\text { level }^{\star}\end{array}$} \\
\hline & $\begin{array}{l}\text { Shared } \\
\text { caseload }\end{array}$ & $\begin{array}{l}\text { Personal } \\
\text { caseload }\end{array}$ & \\
\hline \multicolumn{4}{|l|}{ Continuity: } \\
\hline $\begin{array}{l}\text { Seeing the same midwife at each antenatal } \\
\text { check }\end{array}$ & $16(13)$ & $27(30)$ & 0.002 \\
\hline $\begin{array}{l}\text { Knowing the midwife who looks after you in } \\
\text { labour or delivery }\end{array}$ & $65(52)$ & $47(50)$ & 0.769 \\
\hline Seeing the delivery midwife at postnatal visits & $39(31)$ & $38(40)$ & 0.157 \\
\hline \multicolumn{4}{|l|}{ Communication and control: } \\
\hline $\begin{array}{l}\text { Being given advice about pregnancy and } \\
\text { childbirth }\end{array}$ & $78(61)$ & $60(67)$ & 0.428 \\
\hline $\begin{array}{l}\text { Feeling in control and involved in decision } \\
\text { making }\end{array}$ & $83(65)$ & $54(60)$ & 0.421 \\
\hline
\end{tabular}

check. By contrast, $52 \%(56 / 108)$ of the women from the personal caseload group practice preferred personal continuity of antenatal care and $48 \%(52 / 108)$ did not mind which midwife they saw. Regression analysis indicated that a preference for personal continuity of carer was associated with women's actual experience of antenatal continuity (seeing the same midwife for three checks was associated with a preference for personal continuity $(p=0.056))$ and with the group practice attended (personal caseload group practice was significantly associated with preference for personal continuity of antenatal care, $\mathrm{p}=0.003$ ). Neither sociodemographic variables nor pregnancy history (whether first child) showed any significant associations with a preference for antenatal continuity.

Women's views about continuity in relation to labour or delivery showed that when questioned antenatally most women in both group practices wanted to know their delivery midwife, and $47 \%(116 / 247)$ rated this as very important indeed. However despite a strong desire to be delivered by a midwife they had met before, only $31 \%$ of women attended the "meet your midwife" sessions organised for that purpose.

Ratings of antenatal intrapartum continuity as very important were similar in the postnatal questionnaire (table 3). Nevertheless comparison with the antenatal questionnaire showed

Table 4 Regression analysis of factors associated with women postnatally rating knowing the delivery midwife as very important indeed (odds ratios adjusted for all other variables)

\begin{tabular}{|c|c|c|c|}
\hline Variable & $\begin{array}{l}\text { Odds } \\
\text { ratio }\end{array}$ & $95 \% C I$ & $p$ Value \\
\hline \multicolumn{4}{|l|}{ Social class: } \\
\hline $1 / 2$ & 1 & & \\
\hline $3 / 4 / 5$ & 0.97 & 0.61 to 1.54 & 0.896 \\
\hline \multicolumn{4}{|l|}{ Ethnicity: } \\
\hline White & 1 & & \\
\hline Non-white & 1.70 & 0.79 to 3.65 & 0.178 \\
\hline \multicolumn{4}{|l|}{ Previous child: } \\
\hline None & 1 & & \\
\hline$\geqslant 1$ & 1.58 & 0.80 to 3.11 & 0.190 \\
\hline \multicolumn{4}{|l|}{ Group practice: } \\
\hline Shared caseload & 1 & & \\
\hline Personal caseload & 1.02 & 0.50 to 2.24 & 0.880 \\
\hline \multicolumn{4}{|c|}{ Importance of knowing delivery midwife (antenatal rating): } \\
\hline Rating $0-4$ & 1 & & \\
\hline Rating 5 (very important indeed) & 4.41 & 2.22 to 8.81 & $<0.001$ \\
\hline \multicolumn{4}{|l|}{ Experience in delivery: } \\
\hline Knew delivery midwife & 1 & & \\
\hline Did not know delivery midwife & 0.35 & 0.18 to 0.71 & $<0.004$ \\
\hline
\end{tabular}

${ }^{\star}$ Odds ratio $>1$ indicates category more likely to rate knowing the delivery midwife as very important indeed. some change in women's responses; only two thirds of women who rated knowing the delivery midwife as very important indeed in the antenatal questionnaire gave the same response postnatally. Regression analysis indicated that women's postnatal rating of knowing the delivery midwife as very important indeed was associated both with antenatal ratings of its importance and their actual experience of antenatal-intrapartum continuity (table 4).

Women's postnatal ratings of different aspects of midwifery care indicated that being given advice about pregnancy and childbirth and feeling in control and involved in decision making were more often rated as very important indeed than the three aspects of continuity (table 3).

\section{SATISFACTION WITH CARE}

The question, "how good do you think your antenatal care has been so far?" asked in the antenatal questionnaire showed high levels of satisfaction. About $85 \%$ of women from both group practices gave this a score of three or more on a scale from zero to five, and $28 \%$ (39/139) of women from the shared care group practice and $40 \%(43 / 108)$ of those from the personal care group practice gave a score of five (excellent). There were no significant associations between women's ratings of the quality of antenatal care and any of the respondent or practice variables examined.

Postnatal ratings of care during labour and delivery were similarly positive; over $90 \%$ of women rated their care as good, and $57 \%$ (72/ 127) of women in the shared caseload group practice and $71 \%(67 / 95)$ in the personal caseload group practice rated this as excellent. There were no significant associations between ratings of care during labour and delivery as excellent and any of the variables examined with the exception of group practice attended, with the women from the personal caseload group practice being more likely to rate their care as excellent $(\mathrm{p}=0.010)$.

Responses to an open question in the postnatal questionnaire about the best aspects of care, showed that aspects of continuity of care were mentioned by only $10 \%(22 / 222)$ of women, with the friendliness of the midwives $17 \%(38 / 222)$, and their reassurance and support $21 \%(47 / 222)$ being more often identified. Typical responses were:

"The midwives are always friendly and encouraging and listen to whatever you have to say" (antenatal).

"The best thing about my care was the fact that the midwives were so friendly and understanding" (postnatal).

"It really helped knowing the midwives from the (name) team and especially the close relationship I had with (name) who delivered my baby. Also postnatally it was lovely to again see the midwives I already knew" (postnatal).

\section{Discussion}

This study indicates that personal continuity of carer is not a necessary requirement for high levels of satisfaction with midwifery care. Midwifery schemes based on shared caseloads 
seemed to be as acceptable to women and were associated with high levels of satisfaction. More important than the type of continuity provided were whether women's expectations for continuity were fulfilled, and the consistency and ethos of care in terms of the friendliness of midwives and the reassurance and support they provided. Also, feeling in control and involved in decision making were more often rated as very important than personal continuity of carer, thus emphasising the importance of the content rather than the structure of midwifery based care.

The acceptability of shared caseloads seemed to be a general feature of women's responses with no significant differences in preferences and satisfaction by parity, socioeconomic status, or ethnic group. However, it is recognised that women from ethnic minorities had a high non-response rate, which may have exerted some selective bias. Satisfaction with care among women from ethnic minorities recorded in this study may also have been influenced by four of the 12 midwives belonging to ethnic minorities, and therefore being more likely to be able to respond appropriately to women from different cultural backgrounds.

The significance of previous expectations for satisfaction with care is well known to affect a woman's assessments of health care. ${ }^{13-15}$ As this study showed these expectations may be generated by the service, with the expectation of personal continuity of carer during the antenatal or intrapartum phase or of knowing the delivery midwife, sometimes leading to disappointment if this could not be met. In particular staff holidays and turnover place important restrictions on continuity of care, with two midwives leaving the personal caseload group practice and three leaving the shared caseload practice during the course of the study.

For the development of maternity services, this study suggests that midwifery group practices are associated with high levels of consumer satisfaction, and that the ethos and consistency of care provided by midwives is more important than aiming to achieve a narrow definition of personal continuity of carer. From the women's perspective what seemed to be crucial were their feelings of choice and control, the provision by midwives of reassurance and support, a willingness to listen, and other aspects of what has been referred to as "sentimental work" or the interpersonal aspects of care. ${ }^{16}$

We are very grateful to the women who completed questionnaires, and to the group practice midwives for their support and assistance. We also thank Ruth Dundas for statistical advice. The project was funded by a grant from the King's Fund, with additional support from Tommy's Campaign.

1 Audit Commission. First class delivery: improving maternity services in England and Wales. Abingdon: Audit Commission Publications, 1997.

2 Department of Health. Changing childbirth. Part 1. Report of the Expert Maternity Group. London: HMSO, 1993.

3 Flint C. Continuity of care provided by a team of midwives - the know your midwife scheme. In: Robinson S, Thomson A, eds. Midwives, research and childbirth. Vol 2. Chapman and Hall, London 1991.

4 Oakley A, Rajan L, Grant A. Social support and pregnancy outcome. Br f Obstet Gynaecol 1990;97:155-62.

5 Clement S, Sikorski J, Wilson J, et al. Planning antenatal Clement S, Sikorski J, Wilson J, et al. Planning antenatal
services to meet women's psychological needs. $B r^{\prime} \mathcal{F}$ Midwifery 1997;5:298-305.

6 House of Commons. Second report on the maternity services. HMSO:London 1992

7 McCourt C, Page L. Report on the evaluation of the one-to-one midwifery practice. Thames Valley University, London 1996.

8 Turnbull D, Holmes A, Shields N, et al. Randomised, controlled trial of efficacy of midwife-managed care. Lancet 1996;348:213-8.

9 Institute of Manpower Studies. Mapping team midwifery: a report for the Department of Health. Brighton: Institute of Manpower Studies, 1993.

10 Flessig A, Kroll D, McCarthy M. Is community-led maternity care a feasible option for women assessed at low risk and those with complicated pregnancies? Results of a population based study in South Camden, London. Midwifery 1996;12:191-97.

11 Allen I, Dowling SB, Williams S. A leading role for midwives? London: Policy Studies Institute, 1997.

12 Mason V. Women's experiences of maternity care: a survey manual. London: HMSO, Office of Population Censuses and Surveys, 1993

13 Melia J, Morgan M, Wolfe C, et al. Consumer views of the maternity services: implications for change and quality assurance. F Pub Health Med 1991;13:120-6.

14 Fitzpatrick R, Hopkins A. Problems in the conceptual framework for patient satisfaction research: an empirical framework for patient satisfaction research: an empirical

15 Meredith P. But was the operation worth it? The limitations of quality of life and patient satisfaction research in health ore outcome assessment. f Qual Clin Pract 1996;16:7585 .

16 Strauss A, Fagerhourgh S, Suczek B, et al. Social organisation of medical work. University of Chicago Press, Chicago, 1985 